\title{
Performance of Meteorological and Air Quality Modeling For PM2.5 Simulation, and Impact of Aerosol Direct Effect
}

\author{
Akira Kondo \\ Osaka University \\ 1-1 Yamadaoka, Suita, Osaka Prefecture 565-0871, Japan
}

The first aim of this study is to evaluate the performmance of Weather Research and Forecasting-Community Multiscale Air Quality (WRF-CMAQ) modeling system. Especially fine particulate matter $\left(\mathrm{PM}_{2.5}\right)$ concentrations and its components in Japan which are controlled by heavy local air pollution and long-range transport from East Asia are focused. The daily meteorological variations and the monthly atmospheric pollutants were well captured by the modeling system. $\mathrm{PM}_{2.5}$ concentrations were affected from long-range transport from East Asia. Sulfate of $\mathrm{PM}_{2.5}$ components was reasonably represented but organic aerosol was underestimated by the modeling system. The second aim of this study is to to evaluate the impact of the aerosol direct effect on simulated concentrations of $\mathrm{PM}_{2.5}$ over East Asia by using the online coupled WRFCMAQ modeling system. The simulations showed there were particularly large impacts of the aerosol direct effect in the eastern Asian Continent with high aerosol loading. The largest temporal mean contributions of the direct effect were $40 \%$ decrease in the surface shortwave radiation, $30 \%$ decrease in the planetary boundary layer height, and $20 \%$ increase in the ground-level PM2.5 concentration in the continent. 